\title{
Defect induced cracking and modeling of fatigue strength for an additively manufactured Ti-6Al-4V alloy in very high cycle fatigue regime
}

\author{
Weiqian $\mathrm{Chi}^{1}$, Wenjing Wang ${ }^{1}$, and Chengqi $\mathrm{Sun}^{2}$ \\ ${ }^{1}$ Beijing Jiaotong University \\ ${ }^{2}$ Chinese Academy of Sciences Institute of Mechanics
}

November 30, 2021

\begin{abstract}
Additively manufactured (AM) alloy usually inevitably contains defects during the manufacturing processor or service process. Defects, as a harmful factor, could significantly reduce the fatigue performance of materials. This paper shows that the location and introduced form of defects play an important role in high cycle and very high cycle fatigue (VHCF) behavior of selective laser melting Ti-6Al-4V alloy. S-N curve descends linearly for internal defects induced failure. While for artificial surface defects induced failure, S-N curve descends at first and then exhibits a plateau region feature. We also observed competition of interior crack initiation with the fine granular area feature in VHCF regime. The paper indicates that only the size or the stress intensity factor range of the defect is not an appropriate parameter describing the effect of defects on the fatigue crack initiation. Finally, the effect of artificial surface defects on high cycle and VHCF strength is modeled, i.e. the fatigue strength $\sigma$, fatigue life $N$ and defect size $\sqrt{\text { area }}$ (square root of projection area of defect perpendicular to principal stress direction) is expressed as $\sigma=C N^{a}(\sqrt{\text { area }})^{n}$ for $N_{0}$ and $\sigma=C N_{0}{ }^{a}(\sqrt{\text { area }})^{n}$ for $N[?] N_{0}$, where $C, a$ and $n$ are constants, $N_{0}$ is the number of cycles at the knee point.
\end{abstract}

\section{Hosted file}

manuscript.docx available at https://authorea.com/users/442064/articles/542430-defectinduced-cracking-and-modeling-of-fatigue-strength-for-an-additively-manufactured-ti-6al4v-alloy-in-very-high-cycle-fatigue-regime 